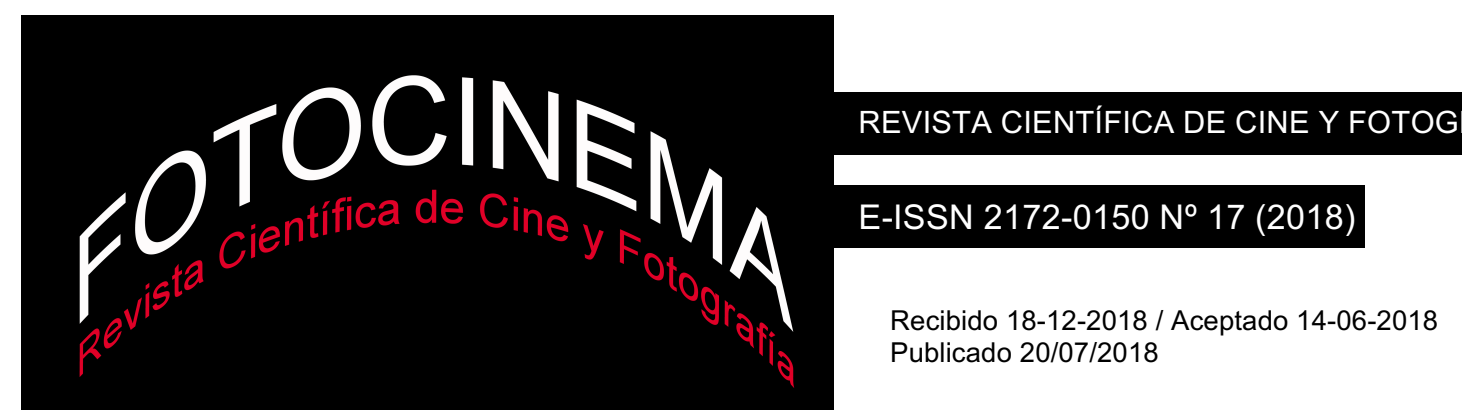

\title{
Chaplin y Cantinflas se ponen serios. Los discursos finales de El gran dictador y Su excelencia
}

\section{Chaplin and Cantinflas get serious. The final speeches of The great dictator and Su excelencia}

\author{
Félix Caballero Wangüemert \\ Universidad de Vigo, España \\ felixcaballero@hotmail.com
}

\section{Resumen:}

En El gran dictador (The Great Dictador, 1940) y Su Excelencia (1966), Charles Chaplin y Mario Moreno, Cantinflas, respectivamente, satirizan el afán de poder de los dirigentes de las grandes naciones. La primera denuncia la Europa de los fascismos, especialmente a la Alemania nazi; y la segunda, el mundo de la Guerra Fría, fundamentalmente a las dos superpotencias de la época: los EEUU y la URSS. A pesar de su naturaleza cómica, las dos películas terminan con sendos discursos absolutamente serios en los que sus protagonistas hacen un semejante llamamiento a favor de la libertad, la paz y la fraternidad de todos los hombres. Este artículo profundiza en los parecidos de los dos alegatos, que parten de una misma situación: un ciudadano común convertido temporalmente en un gran líder político - por confusión o por una serie de circunstancias rocambolescas-, que se encuentra en la grave tesitura de tener que tomar una decisión de la que dependerá el destino de la Humanidad.

\begin{abstract}
:
In The Great Dictator (1940) and Su Excelencia (1966), Charles Chaplin and Mario Moreno, Cantinflas, respectively, satirize the desire of power of leaders of great Nations. The first denounces the Europe of fascisms, especially the nazi Germany; and the second, the world of the Cold War, fundamentally the two superpowers of the time: the US and the USSR. Despite its comic nature, the two films end with two quite serious speeches in which their protagonists make a similar appeal in favor of freedom, peace and the brotherhood of all men. This article delves into the similarities of the two allegations, which are based on the same situation: a common citizen temporarily become a great political leader -by confusion or some bizarre circumstances-, who will have to make a serious decision of which depend on the fate of humanity.
\end{abstract}

Palabras clave:

Charles Chaplin; Cantinflas; El gran dictador; Su Excelencia; comedia; sátira política; parodia

Keywords:

Charles Chaplin; Cantinflas; The Great Dictator; Su Excelencia; Comedy; Political Satire; Parody. 


\section{Introducción}

El gran dictador (The Great Dictator, 1940) y Su Excelencia (1966) son dos de las películas más conocidas de Charles Chaplin y Mario Moreno, Cantinflas, respectivamente. Han pasado a la historia del cine por sus valores cinematográficos, pero también por sus valores humanos, reflejados, fundamentalmente, en los famosos discursos con los que se cierran ambos filmes.

El gran dictador fue estrenada en 1940, al principio de la II Guerra Mundial, y representa una feroz crítica de los fascismos, particularmente del nazismo y de Adolf Hitler, mientras que Su Excelencia vio la luz en 1966, en plena Guerra Fría -solo cuatro años después de la Crisis de los Misiles, que puso al planeta al borde de una guerra nuclear-, y supone una contundente condena de la división del mundo en dos bloques antagónicos, el capitalista y el socialista, y de las dos superpotencias que los lideraban, los Estados Unidos (EEUU) y la Unión de Repúblicas Socialistas Soviéticas (URSS). Pero más allá de esas diferencias, fruto del distinto contexto en que se realizaron, las dos comedias comparten dos características determinantes: ser sendas sátiras políticas basadas en la parodia y el juego de trasuntos, y terminar con un discurso político absolutamente serio que constituye un emocionante llamamiento a la libertad y a la fraternidad humanas.

Entre la ya abundante bibliografía académica o científica sobre Chaplin y Cantinflas (más sobre el primero que sobre el segundo), no encontramos muchos trabajos comparados, y entre estos apenas los hay que se centren en las coincidencias entre los discursos finales de $\mathrm{El}$ gran dictador y $\mathrm{Su}$ Excelencia, a pesar de resultar evidentes y de haber sido señaladas con frecuencia por la crítica cinematográfica.

La influencia de la alocución de Chaplin en la de Cantinflas, filmada veintiséis años después, no es, desde luego, el único influjo de aquel que podemos rastrear en la obra cinematográfica de este, quien por algo fue llamado "el Charlot mexicano" y nunca ocultó su admiración por el cómico inglés ("Don Charles es para mí el más grande”, solía decir), pero no sería justo reducir los paralelismos artísticos y personales entre los dos genios a 
una mera relación de dependencia o sucursalismo del segundo con respecto al primero. No en vano, cuando se conocieron en Ginebra (Suiza) en 1964, Chaplin le dijo al mexicano: “Tú y yo somos los más grandes”.

\section{Objetivos y metodología}

El objetivo de este estudio es hacer un análisis comparativo de los discursos finales de El gran dictador y Su Excelencia, para rastrear la posible influencia del de Chaplin en el de Cantinflas y cómo los dos funcionan a modo de conclusión, moraleja o corolario serio de las sátiras políticas de las que forman parte.

El estudio parte de la hipótesis de que el discurso de Cantinflas está inspirado en el de Chaplin -al igual que toda la película del primero en la del segundo-, de manera que contiene una parecida denuncia del abuso del poder sobre los pueblos y un similar llamamiento al amor universal como instrumento de liberación y de mejora del mundo.

Para conseguir los objetivos se ha utilizado como metodología el análisis de contenido. Tras visionarse los dos filmes completos, se accedió a la transcripción de los dos discursos ${ }^{1} \mathrm{y}$, en una primera fase del análisis, se elaboró un cuadro comparativo con once categorías -localización dentro de la película, duración, narrativa cinematográfica, contexto, emisor, destinatario, advertencias iniciales, citas textuales, estructura, ideas compartidas y elementos humorísticos-, profundizándose más tarde en algunas de ellas, las que aparecen reflejadas más adelante.

El artículo sigue una línea discursiva que va de lo general a lo particular. Se analizan, primero, las semejanzas entre el cine de Chaplin y el de Cantinflas; luego, las similitudes entre El gran dictador y Su excelencia; y finalmente,

1 El discurso de El gran dictador puede ser leído en http://www.taringa.net/post/videos/114635.5/El-discurso-final-de-El-gran-dictador-texto$\mathrm{y}$-video.html. Incluye sendos vídeos del alegato en español y en su versión original en inglés. El alegato de $\mathrm{Su}$ Excelencia puede ser consultado en http://www.grijalvo.com/America_Mejico_Mexico/Cantinflas Discurso Su Excelencia.ht $\underline{\mathrm{m}}$ 
entrando ya de lleno en el núcleo del artículo, los parecidos entre los discursos finales de las dos películas.

\section{Charles Chaplin y Mario Moreno}

Charles Spencer Chaplin, más conocido como Charlie Chaplin (Londres, Inglaterra, 1889-Corsier-sur-Vevey, Suiza, 1977) fue actor, director, escritor, productor y compositor. Con casi noventa películas mudas y sonoras, ha llegado a convertirse en la figura más representativa del cine mudo, el cual le ha dado su fama mundial y la consideración de uno de los grandes genios de la historia del cine. Se hizo popular gracias a Charlot, probablemente el personaje más famoso del séptimo arte.

Siendo apenas un niño empezó a actuar como cómico en compañías ambulantes en el Reino Unido, antes de trasladarse a los Estados Unidos y trabajar en el incipiente cine con la compañía Keystone, de Mack Sennett. En 1919 fundó junto con Mary Pickford, Douglas Fairbanks y David W. Griffith la United Artists. Perseguido por sus ideas progresistas en tiempos del macartismo (o mccarthismo, por el senador Joseph McCarthy), tuvo que abandonar los EEUU y fijar su residencia en Suiza. En 1929, en la primera edición de los Óscar, obtuvo un premio honorífico por actuar, escribir, dirigir y producir El circo (The Circus), galardón que volvería a recibir en 1972, en forma de Óscar honorífico por toda su carrera. En reconocimiento de sus destacados méritos, en 1975 fue nombrado Sir (Caballero) por la reina Isabel II de Inglaterra. Entre su vasta y sobresaliente filmografía destacan títulos como El chico (The Kid, 1920), La quimera del oro (The Gold Rush, 1925), El circo (1928), Luces de la ciudad (City Lights, 1931), Tiempos modernos (Modern Times, 1935) y El gran dictador (1940).

Mario Fortino Alfonso Moreno Reyes, más conocido como Cantinflas (Ciudad de México, 1911-íd., 1993), es considerado, por su gran trayectoria cinematográfica, como el mejor comediante mexicano de todos los tiempos y uno de los más grandes y recordados de habla hispana. Se hizo 
mundialmente célebre con el nombre de su personaje Cantinflas, al que dio vida en la mayoría de los filmes que rodó.

De orígenes muy humildes, se inició en la interpretación en una compañía de cómicos ambulantes con la que recorrió todo México. Rodó más de cincuenta películas. Debutó en el cine en 1936 con No te engañes corazón, aunque no se consagró definitivamente como ídolo indiscutible hasta 1940, en Ahí está el detalle, dirigido por Juan Bustillo Oro. Su director fetiche fue Miguel M. Delgado, con el que hizo treinta y tres películas a partir de El gendarme desconocido (1941). Probó fortuna en Hollywood con La vuelta al mundo en ochenta días (Around the World in Eighty Days, 1956), dirigida por Michael Anderson, en la que actuó junto a David Niven y por la que ganó el Globo de Oro en la categoría de mejor actor de musical o comedia. Repitió la aventura americana en Pepe (1960), dirigida por George Sidney, pero fracasó y no volvió a trabajar en Hollywood. Las dos películas estaban habladas en inglés, idioma al que su revolucionario humor verbal era difícilmente traducible. Entre sus títulos más taquilleros destacan Ni sangre ni arena (1941), Los tres mosqueteros (1942), A volar joven (1947), El bombero atómico (1950), El bolero de Raquel (1956), El analfabeto (1961), El padrecito (1964), Su Excelencia (1967) y El Patrullero 777 (1978).

\section{Semejanzas y diferencias entre los dos cómicos}

\subsection{Semejanzas}

1) Cantinflas, deudor de Charlot

Charlie Chaplin y Mario Moreno crearon sendos personajes eternos -Charlot y Cantinflas, respectivamente- que han escrito páginas de la historia no solo del cine, sino del arte y la cultura popular. La clave de este extraordinario logro radica, sin duda, en su emotividad, humanidad y capacidad de empatía; en su mezcla de astucia y candor, de corazón y de inteligencia natural.

Cantinflas está, sin duda, inspirado en Charlot. Se trata de dos pícaros, término definido por el Diccionario de la Real Academia Española (DRAE) en su quinta y última acepción como "personaje de baja condición, astuto, 
ingenioso y de mal vivir, protagonista de un género literario surgido en España en el siglo XVI”. En efecto, el pícaro nació a la literatura en la España del Siglo de Oro y primera manifestación la encontramos en la novela anónima El Lazarillo de Tormes. Si por “mal vivir” se entiende el engaño o más aún- la comisión habitual de delitos, no puede ser aplicado ni a Charlot ni a Cantinflas. Si ese "mal vivir" incluye el vagabundeo, a Charlot sí, pues, al fin y al cabo, es un vagabundo, pero no a Cantinflas, que, aunque humilde, no deja de tener su hogar.

2) Películas de Cantinflas inspiradas en Chaplin

En sus primeros tiempos, a lo largo de 1939 y 1940, Cantinflas produjo siete cortometrajes para la marca Posa Films. En esta serie de cintas de dos rollos, al modo clásico, de marcada factoría chaplinesca, sentó las bases de lo que sería su personaje cinematográfico en lo sucesivo: Siempre listo en las tinieblas (1939), iJengibre contra dinamita! (1939), Cantinflas y su prima (1940), Cantinflas y los censos (1940), Cantinflas torero (1940), Cantinflas ruletero (1940) -donde hace de taxista- y Cantinflas boxeador (1940).

La mayor huella de Chaplin en Cantinflas la encontramos en El circo (1942). Las similitudes de la película del mexicano con la del británico -estrenada en 1928 con el mismo título, solo que en inglés (The Circus)- son tantas que podríamos decir que la de Cantinflas, más que estar inspirada en la del inglés, es un auténtico remake. No solo el argumento es similar. Hay escenas idénticas en las dos películas, como la de la jaula del león -en la que se meten tanto Charlot como Cantinflas- o la del número del funambulista -los dos se suben al alambre, sustituyendo al artista titular, que está indispuesto-.

Evidente es también la influencia de El gran dictador de Chaplin en $\mathrm{Su}$ Excelencia de Cantinflas. Las dos son sendas sátiras políticas sobre el mundo de su tiempo. Chaplin satiriza el nazismo y Cantinflas, a las superpotencias de la Guerra Fría. Pero en los dos casos encontramos una parodia política sustentada sobre un similar juego de trasuntos. La influencia de El gran dictador en Su Excelencia es especialmente manifiesta en el discurso final de ambos títulos, de lo que se ocupa este trabajo. 
La influencia de El gran dictador en Su Excelencia es evidente, como veremos a continuación, pero en la película de Cantinflas encontramos también ecos de otro título de Chaplin: Tiempos modernos (1936). Las dos terminan igual, mostrando al protagonista alejándose de espaldas acompañado de "la chica" (en Su Excelencia, de Lolita, la secretaria de la Embajada, interpretada por Sonia Infante: en Tiempos modernos, de la joven huérfana, a la que da vida Paulette Godard).

El gran dictador influyó igualmente en Si yo fuera diputado (1951), de Cantinflas: el protagonista es también un humilde barbero, como el de la película de Chaplin, quien, instruido por uno de sus clientes, un anciano abogado, se convierte, primero, en defensor legal de los pobres y, luego, en diputado, lo que le dará pie a hacer memorables discursos, que reiteran los ecos del filme del genio inglés.

\subsection{Diferencias}

Pero el cine de los dos grandes cómicos presenta también algunas diferencias notables:

1) Vagabundo versus peladito

Charlot y Cantinflas son dos pícaros, pero de diferente tipo: el primero es un vagabundo; el segundo, un peladito. El DRAE define pelado, dicho de una persona, como "pobre o de una capa social poco pudiente”. Samuel Ramos, hablando del pelado mexicano, matiza así esa definición:

Es un individuo que lleva su alma al descubierto, sin que nada esconda en sus más íntimos resortes (...). El "pelado" pertenece a una fauna social de categoría ínfima y representa el desecho humano de la gran ciudad. En la jerarquía económica es menos que un proletario y en la intelectual un primitivo (Ramos, 1977, p. 53-54).

Y Carlos Monsiváis dice:

El pelado, el nombre asignado a los lumpenproletarios, el pelado, el que nada lleva y nada tiene, el carente de piel, el que nunca tuvo con qué cubrirse, el paria a quien el diminutivo reduce a su nivel exacto por inofensivo: el peladito (Monsiváis, 2011, p. 101). 
Abundando en arquetipo, Manuel Villegas hace una interesante comparación entre Cantiflas y Buster Keaton:

Es el pelado mexicano, el hombre de las últimas capas sociales, al margen de todo, y que desde allí contempla el mundo, sin mezclarse, sin intervenir. Como el indio de la América Latina, vive junto al blanco sin convivir, ajeno y perdido en su tiempo remoto. Pero cuando Cantinflas se ve obligado a entrar en ese mundo distante, el de todos, lo va volviendo del revés, con la misma palanca de Keaton: la ingenuidad. Que aquí es la candidez pícara y popular del paria social. Pero este origen concreto de su resorte cómico es lo que limita su medio de acción, tan sin confines cuando proviene del absurdo puro (Villegas, 1978, p. 305).

Más allá de sus semejanzas como pícaros, el vagabundo Charlot y el peladito Cantinflas presentan algunas diferencias significativas, como han señalado Bartra (2005) y Santovenia (2011):

a) Charlot responde al ingenio europeo madurado en agudezas intelectuales. Cantinflas actúa conforme con el sentido de las razas mágicas que se expresan en vivencias e intuiciones.

b) Charlot, siendo pobre, aspira a ser todo un caballero. Está decidido a abandonar su vida de infortunio para convertirse en señor. Es un vagabundo, pero lleva puesta ropa de caballero. Como apunta Bartra (2005), su vestido de etiqueta revela una utópica voluntad de cambio. Cantinflas, por su parte, viste de pelado (pantalones caídos, camiseta de manga larga, pañuelo al cuello, restos de una tela que él llama gabardina colgándole de un hombro, sombrero raído que alguna vez fue nuevo y ajados zapatos de un número mayor que el suyo) y no tiene aspiraciones de cambiar su estado social. Y si por casualidad se convierte en señor, procede siempre como pelado, un pelado que es señor solo por accidente. Como dice Garizurieta (en Bartra, 2005), no tiene ninguna aspiración de superarse y "no quiere un mundo mejor ni como sueño; desea vivir como está”.

Con el pelado, Cantinflas descubre el valor del contrasentido. Se da cuenta de que el choque de dos situaciones es la esencia de lo cómico. El pelado es una mezcla de astucia y candor, de corazón y de inteligencia natural. Un tipo que 
es un ideal de supervivencia, pues hay que vencer la fuerza de los poderosos y derrotar al hambre, al desempleo, al cacique político, al diputado corrupto, al deshonesto. Un tipo con una manera de resistir y, llegado el caso, hasta de vencer. Pero para ello se impone una bondad congénita no exenta de esfuerzo, un gran amor hacia los demás, una fe profunda en las propias raíces. Por eso hay una formidable dosis de sentido común que flota siempre sobre la verborrea enrevesada de palabras inútiles y giros extraños (Santovenia, 2011).

3) Humor visual versus humor verbal

El humor de Chaplin es fundamentalmente visual; el de Cantinflas, verbal. Chaplin se basa en el gesto; Cantinflas, en la palabra. Chaplin es el maestro de la pantomima; Cantinflas, del monólogo, aunque no se puede obviar que al arma de doblar la lógica con la lengua sumaba la de redoblar la gracia con el cuerpo, con el jugueteo de su cintura, burladora de ejes, y sus pies bailones, esquivos, rápidos, como la línea de su pensamiento. Como ha escrito Britto, Chaplin liquidó a Charlot antes que acceder a la presión de hacerlo hablar que le imponía el cine sonoro. Por el contrario, Mario Moreno solo puede dar vida a Cantinflas a través del parlante (Britto, 2000, p. 71).

La inmensa mayoría de las películas de Chaplin son mudas. El gran dictador fue, precisamente, su primer filme sonoro², más de veinticinco años después de su debut cinematográfico, y en realidad es mudo en su mayor parte. La película posee todavía momentos de la gran mímica muda de Chaplin: el ballet con el globo terráqueo con música de Richard Wagner, el afeitado con la danza húngara de Brahms, la ceremonia de la moneda en el pudín... (Álvarez, 1990).

En El gran dictador, el silencio representa la inocencia: el barbero judío es prácticamente mudo, mientras que el dictador habla sin interrupción en una jerga de la que solo pueden captarse algunas cosas terribles. Por eso, cuando el barbero tiene que hablar de otra manera, cuando tiene la oportunidad de

\footnotetext{
2 En realidad, en Tiempos modernos, estrenada con anterioridad, el 5 de febrero de 1936, se puede escuchar a Chaplin en una escena cantar durante unos minutos en una lengua ininteligible. No por eso la película se deja de considerar muda.
} 
hacer una gran llamada al mundo, tiene que cederle la palabra a otro: a Charles Chaplin (Álvarez, 1990).

Como maestro del monólogo, Cantinflas entronca más con Groucho Marx, que también hizo del discurso un arma. Con sus habilidades lingüísticas, los dos atacan a los ricos, a los poderosos, a la policía, incluso al Gobierno. Pero mientras Groucho es un sátiro, un bufón, Cantinflas es un cómico. Groucho usa la palabra para fustigar; Cantinflas, para confundir. Groucho intenta derrotar a su interlocutor por KO; Cantinflas, a los puntos, por agotamiento: ante la incomprensión de su discurso, acaba fatigado, desmayado y dispuesto a aceptar lo que le dice. La comicidad de Cantinflas, radica en su "insolencia”, "en su estar en el mundo contra y desde el lenguaje, en su capacidad de tuteo psicológico con quien sea” (Monsiváis, 2011, p. 110). "El habla de Cantinflas va de ningún lado a todas partes, y su fin es vencer (pulverizar) al interlocutor sojuzgado por la cachondería acústica” (Monsiváis, 2011, p. 105).

Sin duda, la gran popularidad del mexicano se debe a que, con sus burlas, hace también una crítica de la injusticia social, pero es una crítica conformista que propone la huida y no la lucha, el escurrimiento y no la pelea. Se convierte en un maestro de las fintas. Se vuelve un ser torcido, alambicado, evasivo e indirecto, dominado por el afán de circunloquio, gracias a un lenguaje pródigo en rodeos, elusiones y retorcimientos, como dice Bartra (2005) siguiendo a Garizurieta. La suya es "la tímida rebelión del hombre que ha perdido la costumbre de rebelarse e ignora contra qué y contra quiénes tiene el deber de rebelarse” (Andrade, 1951, p. 86).

El lenguaje de Cantinflas está hecho de frases entrecortadas y sin sentido, de modismos y formas adverbiales, de palabras que bien entendidas no significan nada y solo son un canto a la incoherencia, al atropello de la sintaxis, a fin de construir una inteligente y cariñosa parodia del sentencioso hablar popular. Suprime verbos, crea adjetivos y de esa pléyade de vocablos surge un cúmulo de carcajadas en el público, tal vez al notar las semejanzas entre su lenguaje y el del comediante. Sus personajes (casi todos una variación del mismo, pero en diferentes papeles y situaciones) entablan una conversación normal para después complicarla al punto de que nadie 
entiende lo que están diciendo. También Lopitos. Sin embargo, en el discurso final de Su Excelencia es meridiano: va al grano y lo expone con una gran claridad.

Esta peculiar manera de Cantinflas ha quedado registrada en el DRAE, que ha aceptado hasta siete términos relacionados todos con la forma de hablar o de actuar del popular personaje. Son estos, por orden alfabético: acantinflado, cantinflada, cantinflas, cantinflear, cantinfleo, cantinflero y cantinflesco. Por cierto que el Diccionario de la Real Academia Española recoge también charlotada, con el significado de "festejo taurino bufo" o "actuación pública, colectiva, grotesca o ridícula”, pero este último vocablo no procede directamente de Charlot, sino de un torero bufo que lo imitaba.

\section{El gran dictador y Su Excelencia}

El gran dictador (1940) fue el sexto largometraje de Chaplin, entre Tiempos Modernos (1936) y Monsier Verdoux (1947). Además de dirigirla e interpretarla, la produjo, escribió el guión y compuso la música. En la interpretación está acompañado por Paulette Goddard, Jack Oakie, Reginald Gardiner, Henry Daniell y Billy Gilbert.

La película significó todo un desafío contra el nazismo, por la ridiculización del régimen y la representación de la persecución de los judíos. Obviamente, es, ante todo, un panfleto de propaganda, que no niega para nada su naturaleza. Sin embargo, es uno de los escasísimos panfletos políticos que han logrado sobrevivir a su motivación inmediata y adquirir valor universal y permanente, gracias a que su reclamo humanitario se capta como legítimo y sentido en profundidad, y no como retórica vacía (Álvarez, 1990). Hay que decir que Chaplin ignoraba que la política racista de Adolf Hitler incluía el exterminio de los judíos; si lo hubiera sabido, El gran dictador probablemente no se habría realizado como una comedia satírica (McDonald et al., 1995, p. 202).

Chaplin interpreta tanto a un humilde barbero judío como a Adenoid Hynkel, el dictador de Tomania (trasunto de Alemania), inspirado en Hitler. Al final, 
el barbero, que había sufrido persecución por el régimen de Hynkel, es confundido con el mismo dictador y tiene que pronunciar un discurso para anunciar el comienzo de la invasión de Osterlich (remedo de Austria) y, con ella, del mundo entero. Pero, lejos de eso, lo que hace es denunciar la dictadura, la codicia, el odio y la intolerancia, y hacer un llamamiento a la libertad y la fraternidad universales.

El gran dictador fue estrenada el 15 de octubre de 1940, un año antes de que EEUU entrara en guerra contra Alemania. Tres acontecimientos habían tenido lugar en 1938, que pudieron ser integrados en el argumento: la anexión de Austria al Tercer Reich en marzo, el Pacto de Acero de Hitler y Benito Mussolini en mayo, y la Noche de los Cristales Rotos en noviembre. El rodaje empezó ocho días después del ataque a Polonia y duró ciento veintisiete días, hasta el 9 de marzo de 1940. En ese espacio de tiempo tuvieron lugar las invasiones de Holanda, Bélgica, Francia y Noruega.

En los Estados Unidos, todavía neutrales, mucha gente pensaba aún que Hitler era un personaje con quien se podía pactar. Las reacciones a la película no tardaron. Los ataques más violentos fueron los de la cadena de periódicos de William Randolph Hearst, decididamente progermánicos. La Liga Nacional de la Decencia, por su parte, incitó a que se prohibiera una película que, en su opinión, era indecente. En 1941, el Senado Norteamericano creó un subcomité que recomendó la prohibición, entre otras, de El gran dictador y El sargento York (Sergeant York, Howard Hawks, 1941), porque, según ellos, incitaban a la guerra.

La entrada de EEUU en la II Guerra Mundial cambió este estado de opinión. Sin embargo, después de la contienda, durante la caza de brujas desatada por el senador Joseph McCarthy, Chaplin fue acusado por el Comité de Actividades Antiamericanas de comunista, inmoral y traidor a la patria, por lo que tuvo que exiliarse en Suiza en 1953 hasta su muerte en 1977.

En España, El gran dictador fue prohibida y solo se pudo estrenar treinta y seis años después, en 1976, cuando ya había fallecido el general Francisco Franco. 
Su Excelencia ${ }^{3}$ es el trigésimo sexto largometraje de Cantinflas, dirigido en 1966 por Miguel M. Delgado, realizador de la mayoría de los títulos del comediante mexicano. Mario Moreno, que además de interpretar la película participó en el guion, está acompañado en los principales papeles por Sonia Infante, Guillermo Zetina y Tito Junco. La película es también conocida como El Embajador, debido a que ese es precisamente el papel que interpreta Mario Moreno y también porque tenía la costumbre desde los años 40 de hacer películas con el nombre de alguna profesión que interpretaba: $E l$ gendarme desconocido (1941)-donde hace de policía-, El mago (1949), El portero (1949), El bombero atómico (1950), El señor fotógrafo (1952), El padrecito (1964) -donde interpreta a un cura-, El señor doctor (1965), El profe (1971), El barrendero (1981).

La película se hace en plena Guerra Fría, conflicto que enfrentó directa o indirectamente a los Estados Unidos y la Unión Soviética por el control del mundo y dividió al planeta en apoyo de uno u otro bando. En 1962, solo cuatro años antes del estreno del filme, la crisis de los misiles cubanos había puesto a la Humanidad al borde de una nueva guerra mundial, que, a diferencia de la II Guerra Mundial, podría suponer la aniquilación del hombre por el uso de las armas nucleares.

Cantinflas denuncia la división del mundo en estos dos bloques políticos e ideológicos y el peligro de su mutua destrucción a través de una posible guerra atómica.

López o Lopitos (Cantinflas) es el humilde canciller - “el último de los funcionarios" - de la embajada de la imaginaria República de $\operatorname{Los} \operatorname{Cocos}^{4}$ en Pepeslavia (trasunto de la URSS), pero termina siendo nombrado embajador “extraordinario y plenipotenciario" después de que su padrino, el doctor Belendre, se consolide como presidente del país tras una serie sucesiva de golpes de Estado. Pepeslavia va a acoger la celebración de una Asamblea

3 No confundir con Su Excelencia el Embajador, película estadounidense de 1964 (solo dos años antes que la de Cantinflas) dirigida por George Englund e interpretada por Marlon Brando, entre otros.

4 Curiosamente, en la primera película de los hermanos Marx -Los cuatro cocos (The Cocoanuts, 1929)-, estos son dueños del hotel Los Cocos, situado en la playa del mismo nombre, en Florida. 
Internacional (remedo de la Asamblea General de las Naciones Unidas) en la que se va a decidir cuál de los dos grandes bloques políticos dominará el mundo: los Colorados (trasunto del socialista, en clara alusión al color rojo que usaban estos países en sus banderas) y los Verdes (remedo del capitalista, en clara alusión al verde color de los billetes de dólar), encabezados, respectivamente por Pepeslavia (remedo de la URSS, como ya se dijo) y Dolaronia (de dólar, trasunto de los Estados Unidos).

La situación está tan igualada que el voto de Los Cocos (es decir, de Cantinflas) resultará decisivo. El embajador se negará a apoyar a uno u otro, y aprovechará para criticar los modelos socialista y capitalista imperantes durante la Guerra Fría y los comportamientos de las dos superpotencias de la época.

La película tuvo muy buen recibimiento por el público, aunque no fue un éxito multimillonario, y también tuvo buena acogida de la crítica, que se mostró en diversos casos comprensiva con Cantinflas en este rol de estrella preocupada, reflexiva o comprometida con diversos valores. Lamentablemente no fue un filme muy conocido fuera de Latinoamérica y quizás por eso no alcanzó la fama de El gran dictador en cuanto a cine de humor-denuncia se refiere.

\section{Similitudes entre las dos películas}

1) Sátira y parodia políticas

Tanto El gran dictador como Su excelencia son una sátira política basada en la parodia. Las dos satirizan y parodian el contexto político de su tiempo, que, de un modo diferente, venía coartando las libertades de las personas y de los pueblos, y condicionando las vidas.

El gran dictador tiene como telón de fondo las vísperas de la II Guerra Mundial y encierra una evidente parodia de los fascismos en general, y del nazismo y de su máximo dirigente, Adolf Hitler, en particular. 
Su Excelencia se construye en plena Guerra Fría y critica y parodia la división del mundo en dos grandes bloques antagónicos: el capitalista y el comunista, dirigidos por los Estados Unidos y la URSS, respectivamente.

2) Juego de trasuntos

Esta doble parodia que suponen las dos películas se traduce, inevitablemente, en un juego de transuntos. Tomania, Osterlich y Bacteria las imaginarias naciones de $E l$ gran dictador- son remedos de Alemania, Austria e Italia, respectivamente. Además, el dictador de Tomania, Adenoid Hynkel, es una parodia de Adolf Hitler; el ministro del interior Garbitsch, de Joseph Goebbels; el ministro de la Guerra Herring, de Hermann Göring; y el dictador de Bacteria, Benzino Napaloni, de Benito Mussolini.

En cuanto a Su Excelencia, los Verdes son un trasunto de los países capitalistas, y los Colorados, de los socialistas. Dolaronia representa a los Estados Unidos, y Pepeslavia, a la URSS. Por último, la Asamblea Internacional hace las veces de la Asamblea General de las Naciones Unidas. Tanto las escenas del auditorio en el que se encuentran los "representantes del mundo" como las del vestíbulo con la escalera de caracol fueron filmados en la Conferencia Interamericana de Seguridad Social, sita en Ciudad de México.

3) Ni Charlot ni Cantinflas

A pesar de que a Chaplin y Moreno los asociamos siempre con sus famosos personajes, ni en El gran dictador encontramos a Charlot ni en $\mathrm{Su}$ Excelencia a Cantinflas. El primero interpreta, por un lado, al dictador Adenoid Hynkel y, por otro, a un humilde barbero judío. Por su parte, el segundo da vida a un sencillo funcionario de embajada que responde al nombre de López, pero es más conocido como Lopitos.

Con todo, ni el barbero judío ni Lopitos dejan de tener ciertas semejanzas con el vagabundo del inglés y el peladito del mexicano, respectivamente. De hecho, aunque en sentido estricto la última película de Charlot es Tiempos modernos, algunos autores han creído ver en El gran dictador la última incursión del famoso personaje en la cinematografía chaplinesca por las 
muchas similitudes que podemos establecer entre él y el barbero. Y no cabe duda de que Lopitos, al igual que el resto de los distintos personajes interpretados por Mario Moreno en las películas en las que no es identificado directamente como Cantinflas5, conserva mucho del espíritu del inmortal peladito.

Sobre la liquidación de Charlot por parte de su autor, Villegas ha escrito que "cuando [Chaplin] trata de expresar nuestro tiempo, Charlot no le sirve" (Villegas, 1978, p. 274). Quizás se pueda decir algo parecido respecto a Mario Moreno y Cantinflas.

4) La dualidad del personaje principal

Tanto el personaje principal de El gran dictador como el de Su Excelencia responden a un mismo patrón, caracterizado por dos notas fundamentales:

a) La dualidad líder político/ciudadano común. Los dos son ciudadanos comunes, corrientes, humildes, a los que una serie de circunstancias azarosas o rocambolescas - una confusión en El gran dictador; el ascenso al poder del padrino del protagonista en Su Excelencia- ponen en el lugar de un gran estadista. El orador de El gran dictador parece ser el dictador Hynkel, cuando en realidad es el humilde barbero judío. El de Su Excelencia es el embajador plenipotenciario de la República de Los Cocos, pero debajo de su distinguido frac quien hay es un simple funcionario que no desea sino volver a ser un ciudadano común.

b) Los dos se ven obligados a asumir una grave responsabilidad. De ellos dependerá el destino del mundo. El discurso del barbero confundido con Hynkel debe dar inicio a la conquista de Osterlich y, después, de todo el planeta. Por su parte, del voto del humilde embajador de Los Cocos dependerá que la Tierra sea dominada por los Verdes o los Colorados. Y los

\footnotetext{
5 En sus últimas catorce películas -desde El analfabeto (1960)-, Mario Moreno no volvió a interpretar propiamente a Cantinflas. Sus personajes se llamaron padre Sebastián (sacerdote), doctor Salvador Medina (médico), Justo Leal y Aventado (abogado), Sócrates García (profesor) o Napoleón Pérez García (barrendero), entre otros, además del Lopitos de $\mathrm{Su}$ Excelencia. Incluso interpretó a Sancho Panza en la coproducción con España Don Quijote cabalga de nuevo (1972). A esta lista hay que añadir los personajes que hizo en sus dos películas rodadas en Hollywood en inglés: Paspartout, en La vuelta al mundo en ochenta días (1956), por la que ganó un Globo de Oro, y Pepe, en el filme del mismo nombre (1960).
} 
dos se rebelan ante ese destino que les han escrito otros. No se dejan llevar por la inercia de las circunstancias, sino que manifiestan un valor y una firmeza extraordinarios. El barbero se resiste a ordenar el inicio de la conquista de Osterlich y Lopitos se niega a votar por alguno de los dos bloques. Y ambos hacen un mismo llamamiento al amor en lugar de al odio, a la cooperación fraterna en vez de al dominio de unos sobre otros.

\section{Parecidos entre los dos discursos}

1) Dos discursos finales no tan finales

Tanto la secuencia del discurso de El gran dictador como la del de $\mathrm{Su}$ Excelencia ponen fin a la película de la que forman parte, pero ninguno de los dos filmes termina estrictamente cuando el orador finaliza su alocución. En los dos casos hay luego una escena final que funciona a modo de corolario del discurso y en la que tiene protagonismo el personaje femenino de la película.

Chaplin se dirige a Hannah, el personaje interpretado por Paulette Godard. Esta, en su casa arrasada de nuevo por los invasores, oye el discurso del barbero en la radio, y se sorprende cuando "Hynkel" se refiere directamente a ella: "Hannah, ¿puedes oírme? Donde quiera que estés, imira a lo alto, Hannah!”. La muchacha dirige la mirada al cielo con esperanza, y sobre su rostro se cierra la pantalla.

En Su Excelencia, Lopitos abandona la sede de la Asamblea Internacional, y Lolita, la secretaria de la Embajada -de la que está enamorado-, sale en su busca. El plano final los muestra juntos, alejándose de espaldas al espectador, en un claro homenaje a Tiempos modernos (1936), que termina igual, con Charlot alejándose de espaldas con la joven huérfana, interpretada también por Paulette Godard.

2) Dos discursos absolutamente serios 
Aunque insertados en sendas comedias, los discursos de El gran dictador y Su Excelencia son absolutamente serios, sin ninguna concesión al humor (en el caso del de Chaplin) o muy pocas (en el de Cantinflas).

En el alegato del mexicano se identifican diez gags, nueve de ellos verbales y uno tan verbal como visual, que son remarcados a veces por las risas del auditorio. Veámoslos:

a) "Me ha tocado en suerte ser el último orador, cosa que me alegra mucho, porque, como quien dice, así me los agarro cansados”.

b) "Y ahora llego yo, que soy de peso pluma, como quien dice, y según donde yo me coloque, de ese lado se irá la balanza”.

c) “... no sería justo que el solo voto de un representante, que a lo mejor está enfermo del hígado, decidiera el destino de seis naciones”. Obsérvese que no se trata de un comentario meramente cómico, sino de un auténtico apunte humorístico, de una gran verdad que a veces tiene consecuencias muy graves.

d) "Para mí todas las ideas son respetables, aunque sean ideítas o ideotas". Crea dos divertidos neologismos con sendos sufijos de cantidad, uno diminutivo y el otro aumentativo, despectivos los dos, en realidad. El efecto humorístico del segundo puede verse reforzado, además, por la similitud fonética de "ideota" con el adjetivo descalificativo "idiota”.

e) "Lo que piense ese señor [...] o ese de allá de bigotitos, que no piensa nada, porque ya se nos durmió, eso no impide que todos nosotros seamos muy buenos amigos”.

f) "Todos creemos que nuestra manera de ser, nuestra manera de vivir, nuestra manera de pensar y hasta nuestro modito de andar son los mejores”.

g) "El día que lo logremos [derribar la barda del odio que nos separa] podremos decir que nos volamos la barda". Barda es un "seto, vallado o tapia que circunda una propiedad”, según el DRAE6. Aquí Cantinflas juega con la polisemia que la palabra volar tiene en México, donde significa también robar.

\footnotetext{
${ }^{6}$ En la versión on line de la 23 edición del DRAE, "barda" tiene dos entradas. La acepción que se recoge aquí es la primera de la segunda entrada.
} 
h) “iEl que quiera ser Colorado que lo sea, pero que no pretenda teñir a los demás!”. Una ingeniosa forma de decir que no intente imponer sus ideas. Juega con el aspecto plástico del término Colorado, que en realidad se refiere a cuestiones ideológicas (los Colorados son los “rojos”, los comunistas).

i) "Siéntense. [Dice unas palabras ininteligibles, en supuesto ruso]. También le hago al ruso. [Va y toma agua y hace gárgaras, pero se da cuenta de que es vodka y apura el vaso]. Ah, pero si es vodka, tramposos”. Este es el único de los diez gags que es tan verbal como visual.

j) “... pero, desgraciadamente, ustedes entendieron mal, confundieron los términos y ¿qué es lo que han hecho?, ¿qué es lo que hacen?: 'Armaos los unos contra los otros”. Vuelve a jugar con las palabras, apoyándose en este caso en la similitud fonética entre “amaos" y “armaos”. Es un gag, como el tercero, con una gran carga de profundidad. Más allá de la broma hay una crítica muy severa.

3) Un emisor y un receptor duales

Como ya se ha dicho en el epígrafe anterior, los personajes protagonistas de las dos películas son sendos ciudadanos corrientes convertidos momentáneamente en grandes estadistas por una serie de circunstancias rocambolescas que se encuentran en la grave tesitura de tener que decidir el destino de toda la Humanidad, y que tienen el valor y la dignidad de no ceder a la inercia de las circunstancias - ni de aferrarse a la privilegiada torre a la que se han visto encaramados por los azares de la vida- y, por el contrario, denunciar la tiranía y el odio de los gobiernos.

Esto se materializa, particularmente, en los dos discursos finales. Es entonces cuando tanto el barbero judío como Lopitos se estrenan en su sorprendente condición de estadistas y tienen que tomar tan grave decisión.

Este carácter dual de los dos personajes protagonistas queda aún más evidente cuando, durante su discurso, advierten a su auditorio de que no son lo que parecen ni quieren serlo. Efectivamente, en las dos alocuciones hay una parecida advertencia en este sentido. 
En El gran dictador, el supuesto Hynkel, que no es otro, en realidad, que el barbero judío, formula la advertencia en la misma apertura de su discurso: "Lo siento, pero yo no quiero ser emperador [del mundo, puesto que Tomania se apresta a conquistar todo el planeta]. Ese no es mi oficio. No quiero gobernar ni conquistar a nadie [...]”.

Y en Su Excelencia, hacia el final de su discurso, Lopitos advierte a su auditorio que les ha hablado "como un simple ciudadano, como un hombre libre”, porque el día anterior dimitió de su alto cargo.

En realidad, el emisor, en los dos casos, tiene tres identidades, porque a estas dos hay que sumar la de los propios autores: finalmente, quienes hablan al mundo no son el dictador y el embajador plenipotenciario, ni el simple barbero y el mero ciudadano en que se ha vuelto a convertir Lopitos, sino Charles Chaplin y Mario Moreno. Esto, precisamente, fue lo que no gustó de El gran dictador a buena parte de la crítica (McDonald et al., 1995, p. 203).

Curiosamente, los destinatarios de los dos discursos presentan también una parecida dualidad: el barbero judío y Lopitos hablan, respectivamente, a las tropas de Tomania y a los delegados de la Asamblea Internacional, especialmente a los de los países Verdes y Colorados, y más en concreto a los de Dolaronia y Pepeslavia, pero también a la Humanidad entera.

El barbero llega a todo el mundo porque su discurso está siendo transmitido por radio. Por eso, antes de dirigirse expresamente a los soldados, dice: “Ahora mismo, mi voz llega a millones de seres en todo el mundo, a millones de hombres, mujeres y niños, víctimas de un sistema que hace torturar a los hombres y encarcelar a gentes inocentes. A los que puedan oírme les digo: no desesperéis". Y después: "Vosotros los hombres tenéis el poder [...]. En nombre de la democracia, utilicemos ese poder actuando todos unidos”.

Por su parte, Lopitos, al hablar a los delegados de la Asamblea Internacional, está hablando también a todos y cada uno de los ciudadanos del mundo a los que estos representan.

Los dos discursos comparten, además, otra característica respecto al destinatario: terminan con la aprobación del auditorio - una nota que invita 
al optimismo-, a pesar de lo osado de su contenido. En el de Chaplin vemos una gran masa ovacionando. Se trata, por cierto, de una imagen real, rescatada de algún documental. Tras el de Cantinflas aplauden todos los delegados, también los de los países Verdes y Colorados, conmovidos.

4) Unas mismas ideas: progreso esclavizante, gobernantes tiranos y amor liberador

Los discursos finales de El gran dictador y de Su excelencia comparten cinco ideas fundamentales:

a) El hombre ha progresado científica y técnicamente, pero ha retrocedido moralmente. En palabras de Cantinflas: "Estamos viviendo un momento histórico en que el hombre científica e intelectualmente es un gigante, pero moralmente es un pigmeo". La receta del mexicano es la misma que la de Chaplin: menos inteligencia y más bondad; menos maquinismo y más humanidad.

b) La ciencia y la técnica deben ser puestas al servicio del hombre, y no al revés. El inglés insta a los hombres a luchar juntos por un mundo "donde la ciencia y donde el progreso nos conduzcan a todos a la felicidad”, y Cantinflas pide a los países grandes que compartan con los pequeños sus adelantos científicos para acabar con el hambre y la miseria, y no para fabricar bombas.

c) Los jefes de los gobiernos hablan de libertad, pero en realidad oprimen a sus pueblos. Chaplin llama a los soldados a dejar de luchar por la esclavitud y Cantinflas denuncia la falsedad de discurso liberador de los Colorados, que en realidad quieren "imponer por la fuerza sus ideas y su sistema político y económico".

d) Los grandes mandatarios tratan a las personas y a los pueblos como medios, no como fines; como cosas, no como seres humanos. Chaplin alerta como ganado, como máquinas, como carne de cañón. Y Cantinflas, como ratones de laboratorio o peones de ajedrez en el tablero de la política internacional.

e) Llamamiento a la Humanidad para que luche por superar el odio y alcanzar la unidad a través del amor fraterno. Chaplin invita a todos a 
ayudarse mutuamente, a hacer felices a los demás, a "derribar la ambición, el odio y la intolerancia”. Y Cantinflas, a vivir como hermanos, a amarse los unos a los otros.

5) Un mismo espíritu evangélico

Como se desprende de las cinco ideas citadas, particularmente de la última, los dos discursos están presididos por un mismo espíritu evangélico, remarcado por sendas citas de Jesús.

Hacia el final de su alegato, Chaplin menciona a Lc 17: 21: "En el capítulo 17 de San Lucas se lee: 'El Reino de Dios está dentro del hombre. No de un hombre ni de un grupo de hombres sino de todos'. iEn vosotros! Vosotros, el pueblo, tenéis el poder".

Cantinflas, por su parte, acude a Jn 13: 34 para recordar el Mandamiento Nuevo: “Amaos los unos a los otros".

Curiosamente, el nombre de Jesús no es explicitado en ninguna de las dos citas. Chaplin se refiere al "capítulo 17 de San Lucas” y Cantinflas lo llama "aquel humilde carpintero de Galilea".

Hay otra cita evangélica que no llega a explicitarse en ninguno de los dos discursos, pero que sobrevuela permanentemente ambos. Cuando Chaplin y Cantinflas cargan contra los dictadores y los estadistas que someten a sus pueblos -particularmente el primero ("los dictadores son libres solo ellos, pero esclavizan al pueblo")- no podemos menos que recordar las palabras de Jesús en Mt 20: 25: "Sabéis que los jefes de las naciones las dominan como señores absolutos, y los grandes las oprimen con su poder”.

Por otro lado, el alegato de Su Excelencia contiene una segunda cita, correspondiente a Benito Juárez, el mitificado político mexicano varias veces presidente de su país entre 1857 y 1872. La frase que de él se recoge es, seguramente, la más famosa de todas las suyas: "El respeto al derecho ajeno es la paz”. 
Tampoco Juárez es identificado por su nombre. Cantinflas se refiere a él como "una de las figuras más humildes pero más grandes de nuestro continente".

\section{Conclusiones}

El Cantinflas de Su Excelencia se mira en el espejo del Chaplin de El gran dictador. El cómico mexicano, como el inglés, satiriza la política internacional de su época a través de la parodia y del juego de trasuntos. En las dos películas podemos identificar, detrás de la ficción, países, dirigentes y políticas reales.

El parecido entre las dos películas se acentúa en sus discursos finales, exentos por completo (el de Chaplin) o casi por completo (el de Cantinflas) de humor, que funcionan como corolarios absolutamente serios de los filmes y tienen la virtud de conmovernos e iluminar nuestra razón a un tiempo.

En los dos casos, un ciudadano común convertido azarosamente en un gran estadista se encuentra en la tesitura de tener que decidir el destino de la Humanidad con una orden (en El gran dictador) o un voto (en $\mathrm{Su}$ Excelencia), pero, lejos de dejarse llevar por la inercia de la situación, se resiste a desempeñar ese papel y tiene el coraje de elevar una grave denuncia de la opresión que los gobiernos del mundo ejercen sobre los hombres y los pueblos, y de formular un llamamiento a toda la Humanidad para que luche unida por superar el odio y alcanzar la paz y la fraternidad. Esta denuncia y este llamamiento responden a un espíritu deudor de los Evangelios cristianos.

\section{Referencias bibliográficas}

Álvarez, L. A. (1990). Los 50 años de El Gran Dictador: las dos caras de Chaplin. Credencial Historia, 3, marzo de 1990, http://www.banrepcultural.org/node/32716 (27/04/2016).

Andrade, R. (1994). El perfil de la quimera. Tema y variaciones de literatura, 3. México, D. F.: UAM, Unidad Azcapotzalco, División de Ciencias Sociales y Humanidades, pp. 71-88. (Artículo de 1951), 
http://zaloamati.azc.uam.mx/bitstream/handle/11191/1346/El_\%2op erfil_de_la_quimera_no_3.pdf?sequence=1 (15/01/2016).

Bartra, R. (2005). La jaula de la melancolía. Identidad y metamorfosis del mexicano. México, D. F.: Debolsillo.

Britto García, L. (2000). Elogio del panfleto y de los géneros malditos. Mérida, Venezuela: El Libro de Arena.

McDonald, G.; Conway, M. y Ricci, M. (1995). Todas las películas de Charlie Chaplin. Barcelona: Odín.

Monsiváis, C. (2011). Mario Moreno, 1911-1993. La imagen perdurable y los momentos momentáneos. En Los ídolos a nado. Barcelona: Debate.

Ramos, S. (1977). El perfil del hombre y la cultura en México. México, D. F.: Espasa Calpe Mexicana. ( $7^{\mathrm{a}}$ edición; la 1 ${ }^{\mathrm{a}}$, de 1951).

Santovenia, R. (2011). Cantinflas, genio del galimatías. Bolpress.com, 3 de marzo de 2011, http://www.bolpress.com/art.php?Cod=2011031704 (15/01/2016).

Villegas López, M. (1978). Charles Chaplin. El genio del cine. Barcelona: Planeta. 